NASA

Technical Memorandum 105392

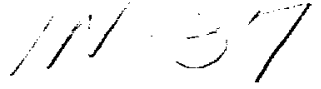

p./7

AVSCOM

Technical Report 91-C-044

\title{
A Basis for Solid Modeling of Gear Teeth With Application in Design and Manufacture
}

Ronald L. Huston

University of Cincinnati

Cincinnati, Ohio

Dimitrios Mavriplis

Miles Laboratories

Elkhart, Indiana

Fred B. Oswald

Lewis Research Center

Cleveland, Ohio

and

Yung Sheng Liu

University of Cincinnati

Cincinnati, Ohio

April 1992

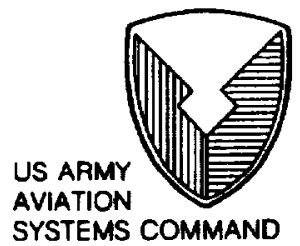




\title{
A BASIS FOR SOLID MODELING OF GEAR TEETH WITH APPLICATION
}

\section{IN DESIGN AND MANUFACTURE}

\author{
Ronald L. Huston \\ University of Cincinnati \\ Cincinnati, Ohio 45221 \\ Dimitrios Mavriplis \\ Miles Laboratories \\ Elkhart, Indiana 46515 \\ Fred B. Oswald \\ National Aeronautics and Space Administration \\ Lewis Research Center \\ Cleveland, Ohio 44135 \\ and \\ Yung Sheng Liu ${ }^{*}$ \\ University of Cincinnati \\ Cincinnati, Ohio $\mathbf{4 5 2 2 1}$
}

\section{SUMMARY}

This paper discusses a new approach to modeling gear tooth surfaces. A computer graphics solid modeling procedure is used to simulate the tooth fabrication processes. This procedure is based on the principles of differential geometry that pertain to envelopes of curves and surfaces. The procedure is illustrated with the modeling of spur, helical, bevel, spiral bevel, and hypoid gear teeth. Applications in design and manufacturing are discussed. Extensions to nonstandard tooth forms, to cams, and to rolling element bearings are proposed.

\section{INTRODUCTION}

A difficult task facing analysts and designers of geared power transmission systems is understanding and utilizing the complex geometry of the gear teeth. Even for involute spur gears where the tooth geometry is generally well understood, the details (e.g., trochoidal geometry and profile modification) are neither simple nor accessible to most designers. For helical, bevel, spiral bevel, and hypoid gears, the geometry is even more complex so that analyses and designs are of necessity approximate and empirical. Optimal gear design is thus elusive. Even if the optimal gear tooth geometry is known, it is distorted under load. Hence, the geometry of meshing gear teeth is generally less than optimal. Indeed, the geometry of meshing gear teeth under load is virtually beyond analytical description.

While the details of gear tooth geometry may not be important in many applications, for precision gears the tooth geometry is the single most important factor influencing transmission kinematics, gear strength, and gear wear. That is, gear tooth geometry has a greater effect upon

\footnotetext{
"Presently at Feng-Chia University, Taichung, Taiwan.
} 
the performance, strength, and life of gearing systems than any other factor. Accordingly, comprehensive gearing kinematic, strength, and life analyses cannot be conducted without an accurate representation of the gear tooth geometry.

In recent years, a number of analysts (refs. 1 to 9) have used the procedures of differential geometry and classical geometrical analyses to describe gear tooth surfaces. These analyses have greatly extended understanding of surface geometry and contact kinematics. Some of these procedures have been combined with numerical methods to obtain tooth contact analyses (refs. 10 to 14). However, there is still a need for more extensive and more accurate representations of gear tooth geometries if analysts and designers are to achieve improvements in transmission efficiency, reliability, and life. Such improvements are especially desirable for precision gears meshing under load. Better representations of gear tooth geometries are also essential for the development of specialized, nonstandard tooth forms.

Recently, a new approach has been proposed to simulate the fabrication of gear teeth by using computer graphics (refs. 15 and 16). This approach has led to a procedure for developing solid models of gears which in turn can be used for studying meshing kinematics, contact stresses, root stresses, and lubrication. Herein we discuss the analytical basis for the procedure used to develop solid models of gears. The procedure is illustrated by developing models of spur, helical, bevel, spiral bevel, and hypoid gears.

This report is divided into five sections, the first of which provides some background material that was needed to develop the procedure for modeling gear tooth surfaces. The succeeding sections examine involute tooth generation, provide some graphical results, discuss the procedure, and present conclusions.

\section{PRELIMINARY ANALYSIS}

\section{Envelopes of Curves and Surfaces: Modeling of Surface Generation}

Consider a plane curve $\mathrm{C}$ defined by the equation

$$
y=f(x)
$$

Suppose that $\mathrm{C}$ has a typical form as in figure 1. Further, let $\mathrm{C}$ be such that it can be moved (or repositioned) in the plane without being distorted. Let $t$ be a parameter determining this repositioning. Then as $t$ varies, the locus of positions of $C$ form the family of curves seen in figure 2. The curve E, representing the limiting location of the family, is the "envelope" of the family.

Suppose that a family of curves is represented in analytical form as

$$
y=f(x, t) \quad \text { or } \quad F(x, y, t)=0
$$


Then it is known that the envelope of the family is determined by the relation (refs. 17 and 18)

$$
\partial \mathrm{F} / \partial \mathrm{t}=0
$$

That is, the elimination of the parameter $t$ between equations (2) and (3) provides an analytical description of $\mathrm{E}$.

To illustrate the construction of an envelope, consider a family of lines such that each line of the family is a fixed distance $r$ from a fixed point $O$, as depicted in figure 3 . Let $\phi$ define the inclination of a typical line $\mathrm{L}$ of the family and let $\theta$ define the inclination of the line normal to $L$ as shown. The equation of $L$ may be written in the standard form

$$
y-y_{p}=m\left(x-x_{p}\right)
$$

where $m$ is the slope of $L$ and where $\left(x_{p}, y_{p}\right)$ are the coordinates of a point $P$ of $L$. If $P$ is the point of intersection of $L$ with the normal line which passes through $O$, then $\mathrm{m}, \theta$, and $\phi$ are related by the expression

$$
\mathrm{m}=\tan \phi=-\cot \theta
$$

From figure 3 we see that the coordinates of $\mathrm{P}$ are

$$
x_{p}=r \cos \theta \quad \text { and } \quad y_{p}=r \sin \theta
$$

Hence, from equation (4), the equation of L may be expressed as

$$
y-r \sin \theta=(-\cot \theta)(x-r \cos \theta)
$$

In the form of equation (2), this becomes

$$
\mathrm{y} \sin \theta+\mathrm{x} \cos \theta-\mathrm{r}=\mathrm{F}(\mathrm{x}, \mathrm{y}, \theta)=0
$$

Equation (8) defines a family of lines with $\theta$ being the "family parameter." Then, from equation (3), if we differentiate with respect to $\theta$, we have

$$
\partial \mathrm{F} / \partial \theta=\mathrm{y} \cos \theta-\mathrm{x} \sin \theta=0
$$

Hence, the equation of the envelope may be obtained by eliminating $\theta$ between equations ( 8 ) and (9). That is, by solving equations (8) and (9) for $x$ and $y$ we obtain

$$
\mathrm{x}=\mathrm{r} \cos \theta \quad \text { and } \quad \mathrm{y}=\mathrm{r} \sin \theta
$$


Finally, by eliminating $\theta$, we have

$$
x^{2}+y^{2}=r^{2}
$$

This is the equation of the envelope of the family of lines. As expected, it is a circle with radius $r$ and center $O$.

The envelope of the edge of a cutting tool may be obtained in a similar manner. The cutting tool envelope is the surface formed by the tool. Hence, using a procedure based upon equations (2) and (3), we may simulate surface generation in a manufacturing process. More specifically, we can simulate and model gear tooth surfaces.

\section{Involute of a Circle}

To establish the procedures for modeling gear tooth surfaces, it is helpful to briefly review the properties of involute curves. Recall that the involute of a circle may be characterized as the locus of positions of the end point of a cord being unwrapped from the circle. Figure 4 depicts an involute I of a circle $C$. Let $P$ be a typical point on the involute and let $\phi$ measure the unwrapping. Then the position vector $p$ locating $P$ relative to the circle center $O$ may be expressed as

$$
\mathbf{p}=\mathbf{x} \mathbf{n}_{\mathrm{x}}+\mathbf{y} \mathbf{n}_{\mathbf{y}}=\mathbf{r} \mathbf{n}_{\mathrm{r}}+\mathbf{r} \phi \mathbf{n}_{\phi}
$$

where $x$ and $y$ are the horizontal and vertical coordinates of $P, r$ is the circle radius, and $\mathbf{n}_{x}, \mathbf{n}_{\mathbf{y}}, \mathbf{n}_{\mathrm{r}}$, and $\mathbf{n}_{\phi}$ are the horizontal, vertical, radial, and tangential unit vectors as shown in figure 4. The unit vectors are then related by the expressions

$$
\mathbf{n}_{\mathbf{r}}=\sin \phi \mathbf{n}_{\mathbf{x}}+\cos \phi \mathbf{n}_{\mathbf{y}} \quad \text { and } \quad \mathbf{n}_{\phi}=-\cos \phi \mathbf{n}_{\mathbf{x}}+\sin \phi \mathbf{n}_{\mathbf{y}}
$$

When a substitution for $n_{r}$ and $n_{\phi}$ from equation (13) is made in equation (12), $x$ and $y$ are seen to be related to $r$ and $\phi$ by the expressions

$$
\mathrm{x}=\mathrm{r} \sin \phi-\mathrm{r} \phi \cos \phi \quad \text { and } \quad \mathrm{y}=\mathrm{r} \cos \phi+\mathrm{r} \phi \sin \phi
$$

Equations (14) are parametric equations defining the involute. The slope of the involute at $\mathrm{P}$ is then

$$
\mathrm{dy} / \mathrm{dx}=(\mathrm{dy} / \mathrm{d} \phi) /(\mathrm{dx} / \mathrm{d} \phi)=\cot \phi
$$




\section{Use of Computer Graphics}

The concept of parametric equations defining the envelope of a family of lines can be used as a basis for computer graphics modeling of involute spur gear teeth. To illustrate, consider a perfectly plastic circular disk rolling in a straight line, as in figure 5. Let the disk encounter a rigid protrusion, such as an isosceles triangle, on the rolling surface. After the disk rolls over the protrusion, the impression (or footprint) left in the plastic disk represents the envelope of the sides of the triangle relative to a coordinate system fixed in the disk. This envelope is an involute of a circle whose radius is equal to that of the rolling disk less the triangle height (ref. 15).

This simulation can be used to represent the manufacture of an involute spur gear tooth: Let the rolling disk be replaced by a gear blank rolling on its base circle as seen in figure 6 . When the rolling gear blank encounters a cutter in the shape of an involute rack tooth, the impression on the blank is the gap between the teeth of an involute spur gear. Furthermore (as demonstrated in refs. 15 and 16), the simulation also defines the trochoidal geometry at the root of the gear teeth.

Figure 6 shows how this procedure was used with computer graphics software (ref. 19) to simulate a gear blank rolling over a rack cutter.

The analysis of reference 15 and the image of figure 6 show that computer graphics can be used to simulate involute gear tooth manufacture, as with a rack cutter or hob cutter. However, the success of this simulation raises several questions: (1) Can the simulation be extended to the manufacture of other tooth forms, that is, to noninvolute tooth forms? (2) Can the simulation be extended to the manufacture of other gear forms, for example, to bevel, spiral-bevel, and hypoid gears? (3) Can a procedure be developed for simulating surface generation in general? and (4) Is there an analytical basis for such simulations? We address these questions in the following sections.

\section{ENVELOPE OF A ROLLING INVOLUTE CUTTER}

To develop an analytical basis for the graphical simulation, consider first two rolling disks $W_{1}$ and $W_{2}$ whose radii $r_{1}$ and $r_{2}$ define pitch circles of mating spur gears (fig. 7 ). Let a cutter shaped like an involute tooth be placed on $W_{2}$ and let $G_{1}$ be a gear blank placed on $W_{1}$. The cutter will leave a gear tooth impression (or footprint) on the gear blank as $W_{1}$ rolls with $W_{2}$.

To obtain an analytical representation of the impression, it is helpful to introduce coordinate axes fixed in $W_{1}$ and $W_{2}$, as shown in figure 8. Let $\hat{X}-\hat{Y}$ and $X-Y$ be Cartesian axes systems fixed in $W_{1}$ and $W_{2}$ with origins $O_{1}$ and $O_{2}$. Let $\alpha$ be the angle between $\hat{X}$ and $X$ as $W_{1}$ rolls on $W_{2}$. Let $L$ be the line connecting the centers $O_{1}$ and $O_{2}$. Let $\theta_{1}$ be the angle between $\hat{Y}$ and $L$ and let $\theta_{2}$ be the angle between $Y$ and $L$. Let $P$ be a typical point in space with coordinates $\hat{x}, \hat{y}$ relative to $\hat{X}-\hat{Y}$ and coordinates $x, y$ relative to $\mathrm{X}-\mathrm{Y}$. Then from figure 8 , these coordinates are related by the expressions

$$
x=\left(r_{1}+r_{2}\right) \sin \theta_{2}+\hat{x} \cos \alpha+\hat{y} \sin \alpha
$$

and

$$
y=\left(r_{1}+r_{2}\right) \cos \theta_{2}-\hat{x} \sin \alpha+\hat{y} \cos \alpha
$$


and

$$
\hat{\mathrm{x}}=\left(\mathrm{r}_{1}+\mathrm{r}_{2}\right) \sin \left(\alpha-\theta_{2}\right)+\mathrm{x} \cos \alpha-\mathrm{y} \sin \alpha
$$

$$
\hat{\mathrm{y}}=-\left(\mathrm{r}_{1}+\mathrm{r}_{2}\right) \cos \left(\alpha-\theta_{2}\right)+\mathrm{x} \sin \alpha+\mathrm{y} \cos \alpha
$$

Observe that, since $W_{1}$ rolls on $W_{2}, \alpha$ and $\theta_{2}$ are not independent. Indeed, from figure 8 we see that

$$
\alpha=\theta_{1}+\theta_{2}
$$

The rolling condition requires that

$$
\mathbf{r}_{1} \theta_{1}=\mathbf{r}_{2} \theta_{2}
$$

Hence, by solving for $\theta_{2}$ and for $\alpha-\theta_{2}$, we have

$$
\theta_{2}=\frac{r_{1} \alpha}{r_{1}+r_{2}} \quad \text { and } \quad \alpha-\theta_{2}=\frac{r_{2} \alpha}{r_{1}+r_{2}}
$$

Suppose that the graph of a function $y=f(x)$ describes the cutter profile in $W_{2}$. Then from equations (16), the cutter profile may be represented in $W_{1}$ (and, hence, also in gear blank $\left.\mathrm{G}_{1}\right)$ as

$$
\mathrm{y}(\hat{\mathrm{x}}, \hat{\mathrm{y}}, \alpha)=\mathrm{f}[\mathrm{x}(\hat{\mathrm{x}}, \hat{\mathrm{y}}, \alpha)] \quad \text { or } \quad \mathrm{F}(\hat{\mathrm{x}}, \hat{\mathrm{y}}, \alpha)=0
$$

The representation of the cutter profile in $G_{1}$ thus depends upon the roll angle $\alpha$. Hence, from equation (3), the envelope of the cutter profile in $G_{1}$ is determined from equation (21) and the expression

$$
\partial \mathrm{F}(\hat{\mathrm{x}}, \hat{\mathrm{y}}, \alpha) / \partial \alpha=0
$$

By substituting for $\mathrm{x}$ and $\mathrm{y}$ from equations (16) into equation (21) and by using equation (20), we have

$$
\begin{aligned}
& \left(r_{1}+r_{2}\right) \cos \left(\frac{r_{1} \alpha}{r_{1}+r_{2}}\right)-\hat{x} \sin \alpha+\hat{y} \cos \alpha \\
& =f\left[\left(r_{1}+r_{2}\right) \sin \left(\frac{r_{1} \alpha}{r_{1}+r_{2}}\right)+\hat{x} \cos \alpha+\hat{y} \sin \alpha\right]
\end{aligned}
$$


Then by performing the differentiation of equation (22), we obtain the expression

$$
\begin{aligned}
-\mathrm{r}_{1} \sin \left(\frac{\mathrm{r}_{1} \alpha}{\mathrm{r}_{1}+\mathrm{r}_{2}}\right) & -\hat{\mathrm{x}} \cos \alpha-\hat{\mathrm{y}} \sin \alpha=\frac{\mathrm{df}}{\mathrm{dx}} \frac{\mathrm{dx}}{\mathrm{d} \alpha} \\
& =\left(\frac{\mathrm{df}}{\mathrm{dx}}\right)\left[\mathrm{r}_{1} \cos \left(\frac{\mathrm{r}_{1} \alpha}{\mathrm{r}_{1}+\mathrm{r}_{2}}\right)-\hat{\mathrm{x}} \sin \alpha+\hat{\mathrm{y}} \cos \alpha\right]
\end{aligned}
$$

By using equations (16) and (20), equation (24) may be expressed in terms of $x$ and $y$ as

$$
-x+r_{2} \sin \left(\frac{r_{1} \alpha}{r_{1}+r_{2}}\right)=\left(\frac{d f}{d x}\right)\left[y-r_{2} \cos \left(\frac{r_{1} \alpha}{r_{1}+r_{2}}\right)\right]
$$

Suppose that the cutter profile is an involute (as in eq. (14)) with parameter $\phi$. Then from equation (15), $\mathrm{df} / \mathrm{dx}$ equals $\cot \phi$ and equation (25) becomes

$$
-x+r_{2} \sin \left(\frac{r_{1} \alpha}{r_{1}+r_{2}}\right)=(\cot \phi)\left[y-r_{2} \cos \left(\frac{r_{1} \alpha}{r_{1}+r_{2}}\right)\right]
$$

Multiplying by $\cos \phi$ and rearranging terms results in

$$
x \sin \phi+y \cos \phi=r_{2} \cos \left(\phi-\frac{r_{1} \alpha}{r_{1}+r_{2}}\right)
$$

Observe, however, from equation (14) that

$$
\mathrm{x} \sin \phi+\mathrm{y} \cos \phi=r
$$

Thus, we have

$$
\cos \left(\phi-\frac{r_{1} \alpha}{r_{1}+r_{2}}\right)=1 \text { or } \phi=\frac{r_{1} \alpha}{r_{1}+r_{2}}
$$

Finally, consider the expression of the involute cutter profile in $G_{1}$ : by substituting for $x$ and $y$ from equations (14) into (17) and by using equation (20), we obtain 


$$
\begin{aligned}
& \hat{\mathbf{x}}=\left(\mathrm{r}_{1}+\mathrm{r}_{2}\right) \sin \left(\frac{\mathrm{r}_{1} \alpha}{\mathrm{r}_{1}+\mathrm{r}_{2}}\right)+\mathrm{r}_{2} \sin (\phi-\alpha)-\mathrm{r}_{2} \phi \cos (\phi-\alpha) \\
& \hat{\mathrm{y}}=-\left(\mathrm{r}_{1}+\mathrm{r}_{2}\right) \cos \left(\frac{\mathrm{r}_{2} \alpha}{\mathrm{r}_{1}+\mathrm{r}_{2}}\right)+\mathrm{r}_{2} \cos (\phi-\alpha)+\mathrm{r}_{2} \sin (\phi-\alpha)
\end{aligned}
$$

Observe from equation (24) that

$$
\phi-\alpha=-\left(\frac{\mathrm{r}_{1} \alpha}{\mathrm{r}_{1}+\mathrm{r}_{2}}\right)=-\left(\frac{\mathrm{r}_{2}}{\mathrm{r}_{1}}\right) \phi=\beta
$$

where the parameter $\beta$ is defined by the final equality. Hence, by substituting into equation (30), we have

$$
\hat{\mathbf{x}}=\mathrm{r}_{1} \sin \beta-\mathrm{r}_{1} \beta \cos \beta \quad \text { and } \quad \hat{\mathrm{y}}=-\mathrm{r}_{1} \cos \beta-\mathrm{r}_{1} \beta \sin \beta
$$

By comparing equations (32) with equations (14), we see that they have the same form. Therefore, the envelope (or footprint) of the involute cutter in $G_{1}$ is itself an involute.

\section{COMPUTER GRAPHICS RESULTS}

A computer graphics software system (ref. 19) was used to simulate the gear cutting process for several types of gears. First, to simulate an involute rack cutter, a plastic disk was rolled over a series of rigid straight-sided protrusions (fig. 6). The disk was examined and found to have involute teeth cut into its surface. Finally, a similar procedure was used to generate images of helical, bevel, spiral bevel, and hypoid gears. Figures 9 to 12 show the simulations.

\section{DISCUSSION}

The discussion presented earlier on the envelope of a family of curves establishes the basis for a computer graphics procedure for simulating gear tooth generation. The analysis shows, for example, that the envelope of an involute protrusion is an involute. While this is not a new or unexpected result (indeed, it is the basis of spur gear fabrication by hobbing), the analysis establishes that the result is based on the principles of differential geometry.

The computer graphics procedure described in this report provides a realistic simulation of gear generation processes. The only simplifying assumptions involved are the assumptions of a perfectly rigid cutting tool and a perfectly plastic workpiece (gear blank).

The significance of this result is that tooth form complexity need no longer be a hindrance to comprehensive analysis and design; that is, the computer graphic procedure is unaffected by 
the complexity of the tooth form whereas analytical procedures quickly become intractable as the complexity increases. Hence, the procedure can be applied without modification for the analysis of bevel gear, hypoid gear, and noninvolute, nonstandard gear tooth forms.

The computer graphics procedure can also be used to define the geometry for a finiteelement model of a tooth form. The combined graphical and finite-element analysis is thus a design tool for studying stresses and deformations in tooth forms, particularly in the less well understood tooth forms of spiral bevel and hypoid gears. Noninvolute and nonstandard tooth forms are also readily accommodated. Indeed, the computer graphics procedure can be used to modify, develop, and examine new forms of conjugate teeth. It can also be used to study fillet geometry, tip relief, dressing operations, and contact patch geometry.

The computer graphics procedure provides accurate simulations in a short time. For example, the simulations shown in figures 9 to 12 , although they have only two or three teeth, are generally sufficient for stress analysis; noncontacting teeth have little effect upon the stresses of contacting teeth. The run time for a spiral bevel gear simulation is approximately 1 hour on an HP model 350 computer.

The computer graphics procedure can also be applied to the manufacture of tooth surfaces. Tooth forms from arbitrary cutter shapes can be predicted. Conversely, cutter shapes producing a desired tooth form can be determined. Specifically, the cutter profile for any given tooth form is the conjugate of that tooth form. This conjugate can be generated using computer graphics by rolling a blank disk over the desired tooth form. That is, the shape of the cutter profile is the same as the impression left on the blank by the desired tooth form.

Finally, the computer graphics procedure can be extended to study surface generation in general, and applications can be made to cam design, bearing design, and surface design of arbitrary rolling elements. Analogous procedures may be developed for simulating the manufacture of skin surfaces such as automobile fenders, airfoils, and ship hulls.

\section{CONCLUSIONS}

An analysis of the envelopes of families of curves, based on differential geometry, was presented as the foundation for a solid modeling procedure. Commercial computer graphics software was used to simulate gear tooth generation. The conclusions are

1. An analytical basis for numerical computer graphic modeling of gear tooth surfaces has been established.

2. The computer graphic procedure can be used for the modeling and analyses of a wide variety of tooth forms, including spur gears, helical gears, bevel gears, spiral bevel gears, hypoid gears, and nonstandard gears.

3. The procedure may be extended to study the design and manufacture of rolling surfaces in general and, ultimately, skin surfaces. 


\section{REFERENCES}

1. Baxter, M.L., Jr.: Lattice Contact in Generated Spiral Bevel Gears. J. Mech. Des., vol. 100, 1978, pp. 41-44.

2. Baxter, M.L., Jr.: Basic Geometry and Tooth Contact of Hypoid Gears. Ind. Math., vol. 11, pt 2, 1961, pp. 19-43.

3. Huston, R.L.; and Coy, J.J.: Ideal Spiral Bevel Gears-A New Approach to Surface Geometry. J. Mech. Des., vol. 103, 1981, pp. 127-133.

4. Huston, R.L.; Lin, Y.; and Coy, J.J.: Tooth Profile Analysis of Circular-Cut, Spiral Bevel Gears. J. Mech. Transm. Autom. Des., vol. 105, 1983, pp. 132-137.

5. Litvin, F.L.: Relationship Between the Curvatures of Tooth Surfaces in Three-Dimensional Gear Systems. NASA TM-75130, 1977.

6. Litvin, F.L.; Krylov, N.N.; and Erikhov, M.L.: Generation of Tooth Surfaces by TwoParameter Enveloping. Mech. Mach. Theor., vol. 10, 1975, pp. 365-373.

7. Litvin, F.L., et al.: Method for Generation of Spiral Bevel Gears with Conjugate Gear Tooth Surfaces. J. Mech. Transm. Autom. Des., vol. 109, 1987, pp. 163-170.

8. Litvin, F.L.; Rahman, P.; and Goldrich, R.N.: Mathematical Models for the Synthesis and Optimization of Spiral Bevel Gear Tooth Surfaces. NASA CR-3553, 1982.

9. Tsai, Y.C.; and Chin, P.C.: Surface Geometry of Straight and Spiral Bevel Gears. J. Mech. Transm. Autom. Des., vol. 109, 1987, pp. 443-449.

10. Litvin, F.L.; and Zhang, J.: Topology of Modified Helical Gears and Tooth Contact Analysis ('TCA) Program. NASA CR-4224, 1989.

11. Litvin, F.L.; Tsung, W.-J.; and Coy, J.J.: Generation of Spiral Bevel Gears With Zero Kinematical Errors and Computer Aided Tooth Contact Analysis. NASA TM-87273, 1987.

12. Litvin, F.L., et al.: Generated Spiral Bevel Gears: Optimal Machine-Tool Settings and Tooth Contact Analysis. SAE Paper 851573, 1985.

13. Litvin, F.L.; Tsung, W.-J.; and Lee, H.-T.: Generation of Spiral Bevel Gears with Conjugate Tooth Surfaces and Tooth Contact Analysis. NASA CR-4088, 1987.

14. Remsen, J.A.; and Carlson, D.R.: The Application of Tooth Contact Analysis to Tractor Bevel Gearing. Gleason Publication No. AD 1906, Gleason Works, 1968.

15. Chang, S.H.; Huston, R.L.; and Coy, J.J.: A Computer Aided Design Procedure for Generating Gear Teeth. ASME Paper 84-DET-184, 1984. 
16. Huston, R.L.; Mavriplis, D.; and Oswald, F.B.: Computer Aided Design of Spur Gear Teeth. International Power Transmission and Gearing Conference, 5th, ASME, 1989, pp. 539-545.

17. Graustein, W.C.: Differential Geometry. Macmillan, 1935, p. 64.

18. Struik, D.J.: Lectures on Classical Differential Geometry. Addison-Wesley, 1961, pp. 73, 167.

19. I-DEAS (Integrated Design and Engineering Analysis Software) Structural Dynamics Research Corporation (SDRC), Milford, Ohio.
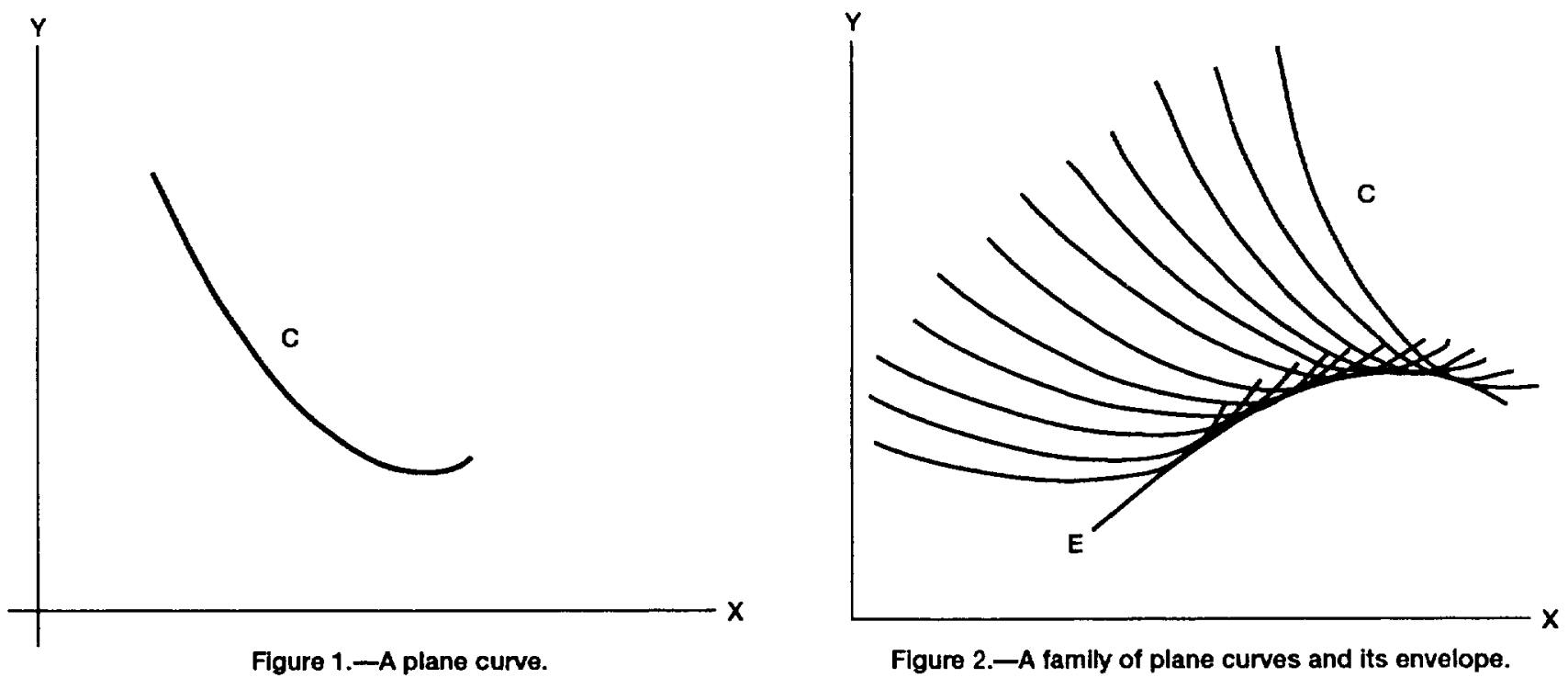

Figure 2.-A famlly of plane curves and its envelope.

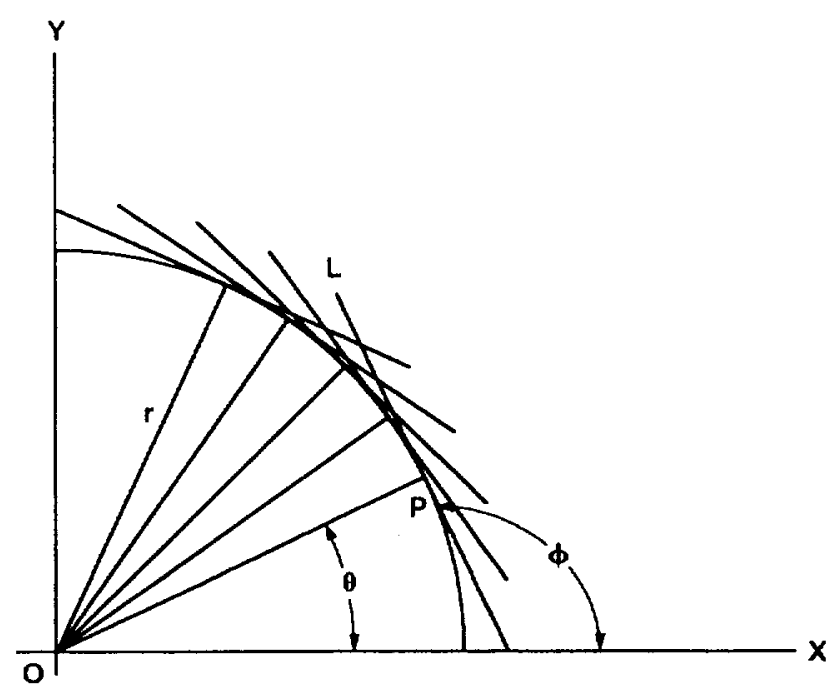

Figure 3.-A family of lines equidistant from a point. 


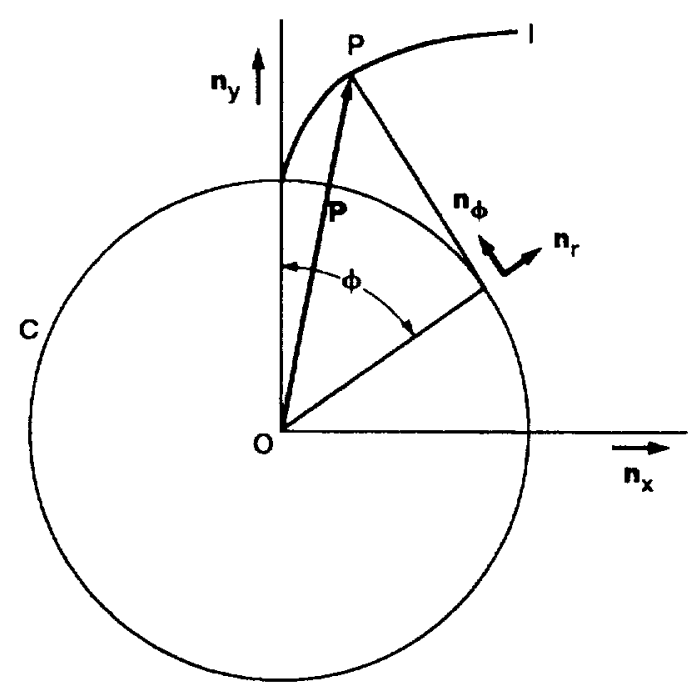

Figure 4.- Involute geometry.

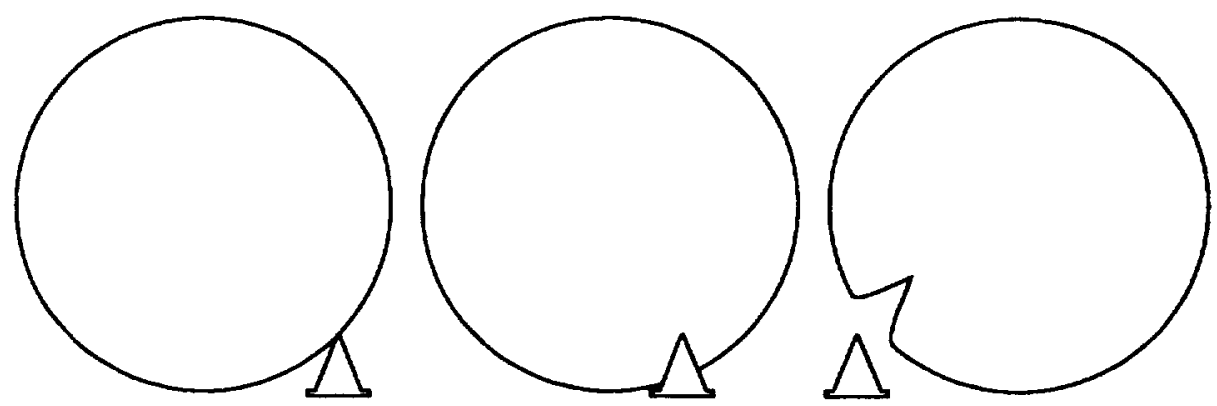

Figure 5.-A plastic disk rolling over a rigid triangular protrusion.
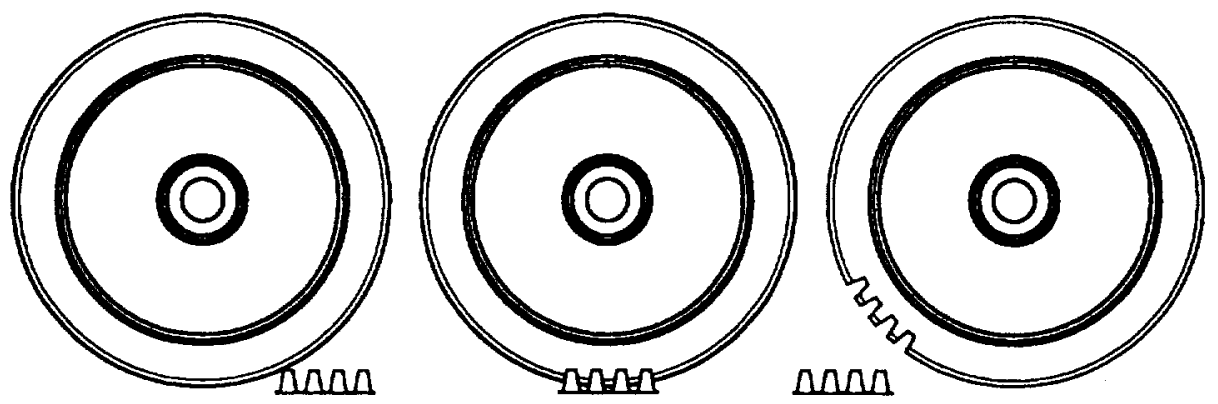

Figure 6.-A gear blank rolling over a rack cutter. 


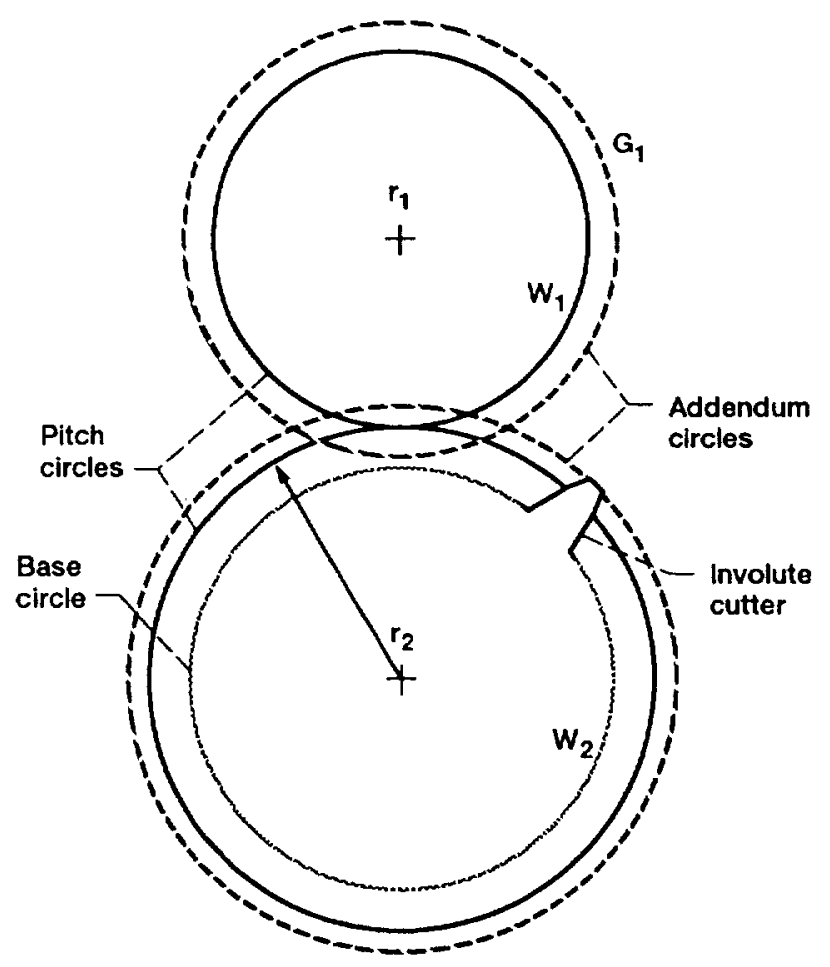

Figure 7.-Rolling disks simulating meshing gears.

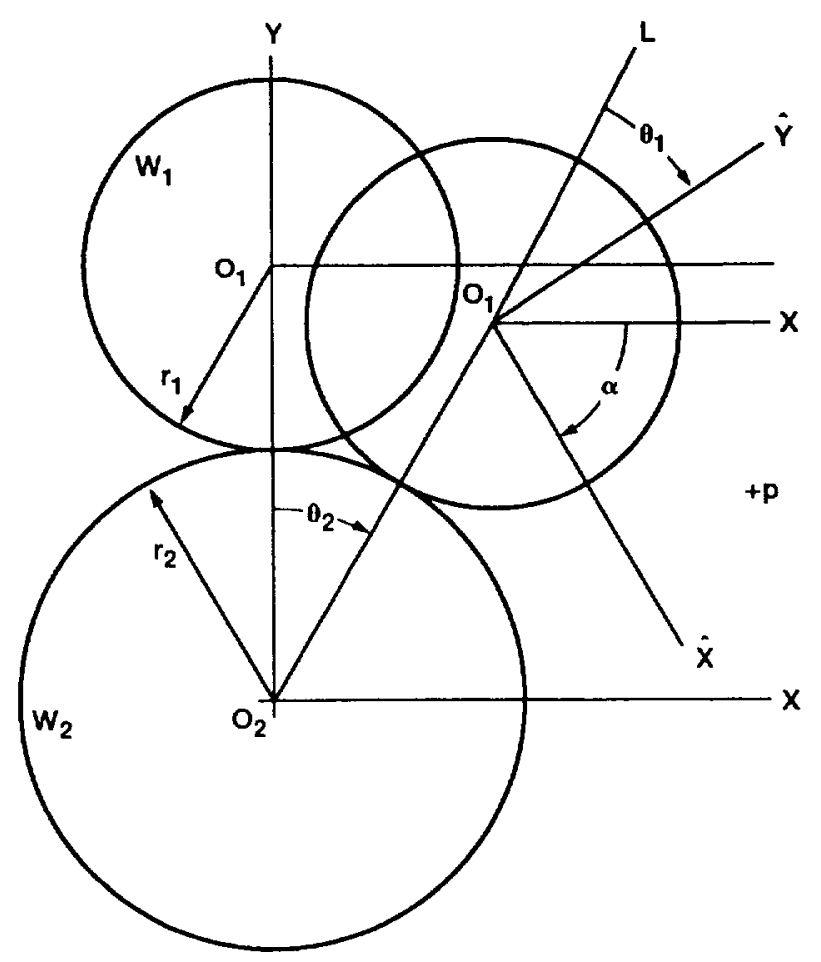

Figure 8.-Coordinate axes in the rolling disks. 


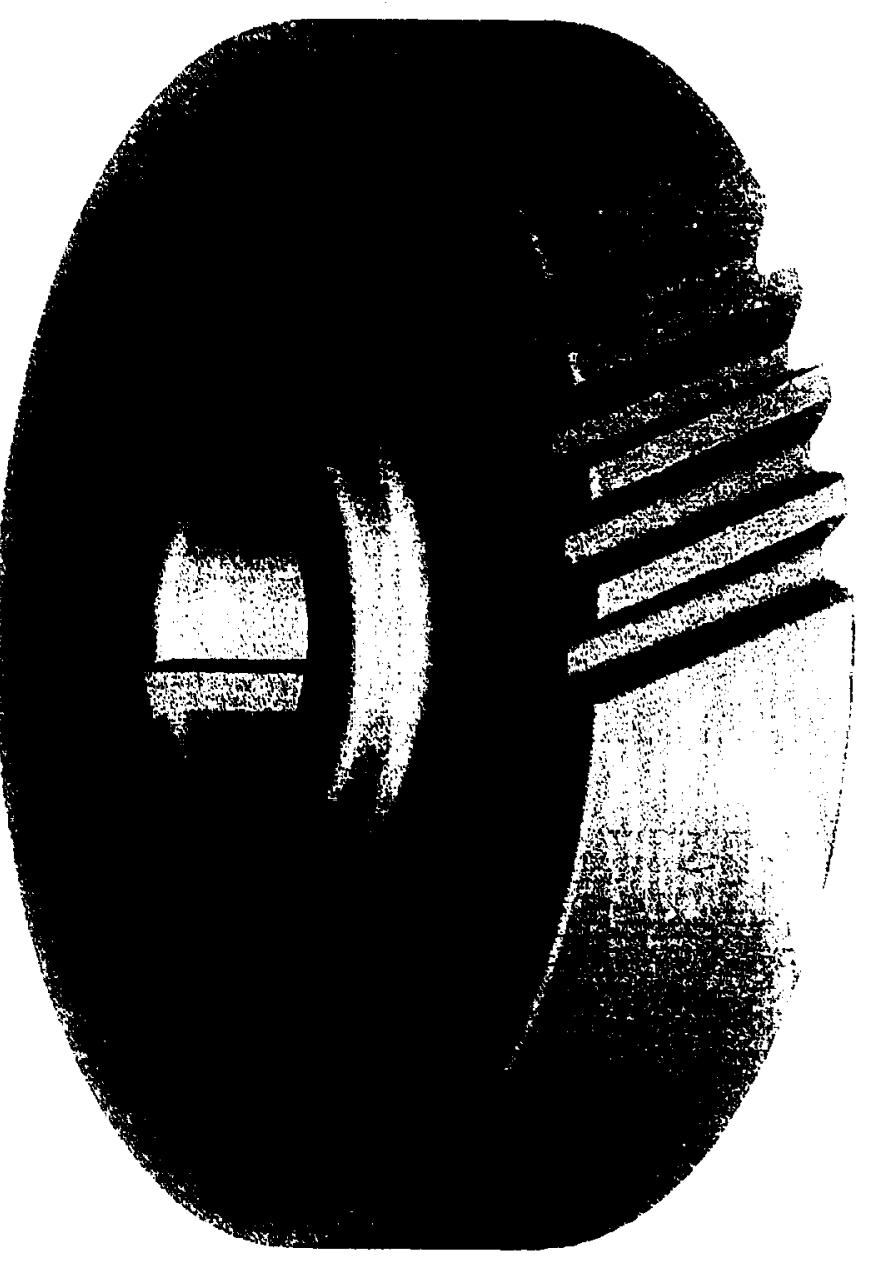

Figure 9.-Helical gear simulation.

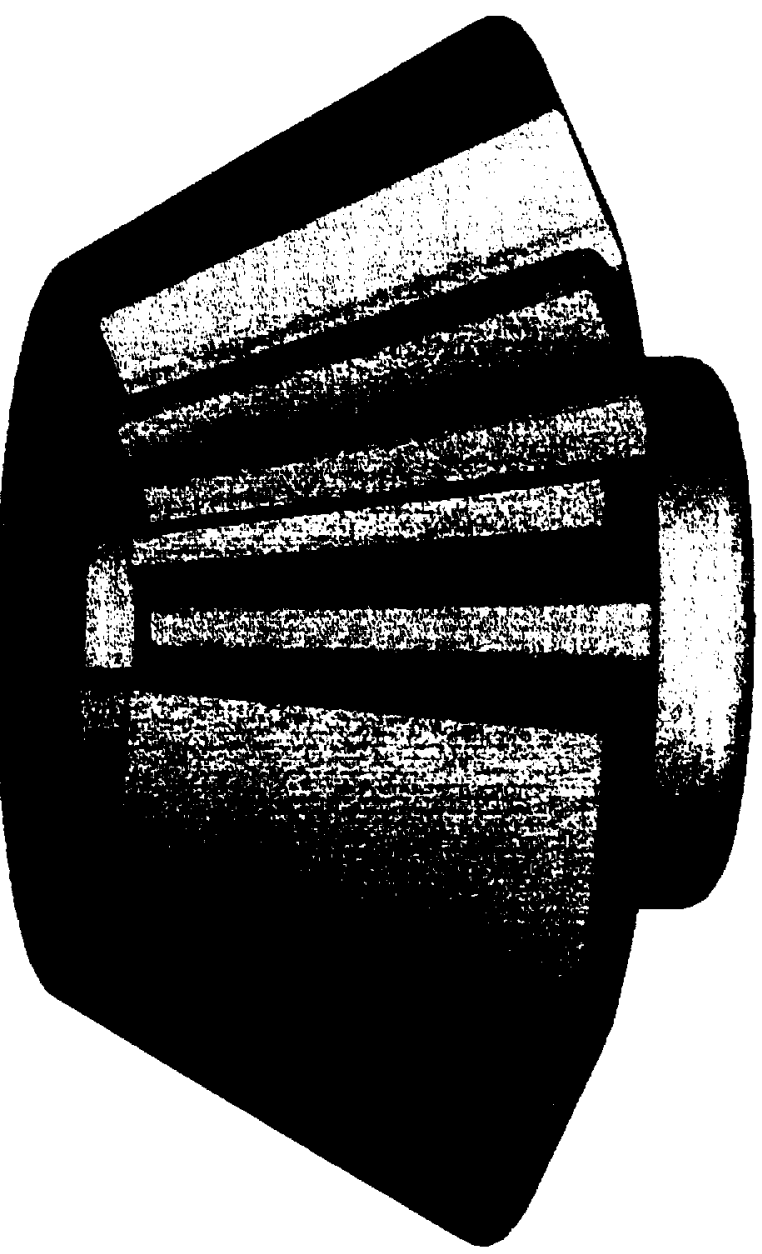

Figure 10.-Bevel gear simulation. 


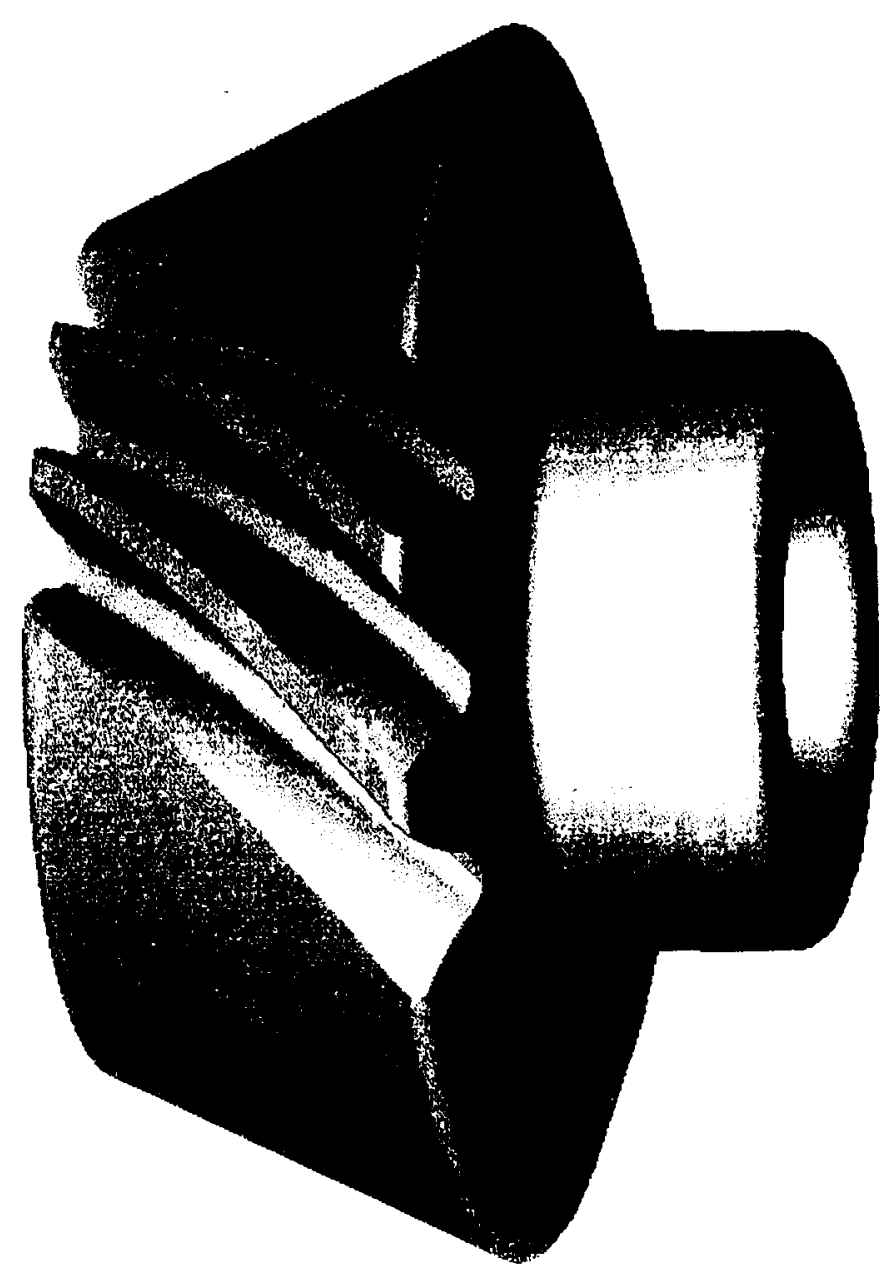

Figure 11.-Spiral bevel gear simulation.

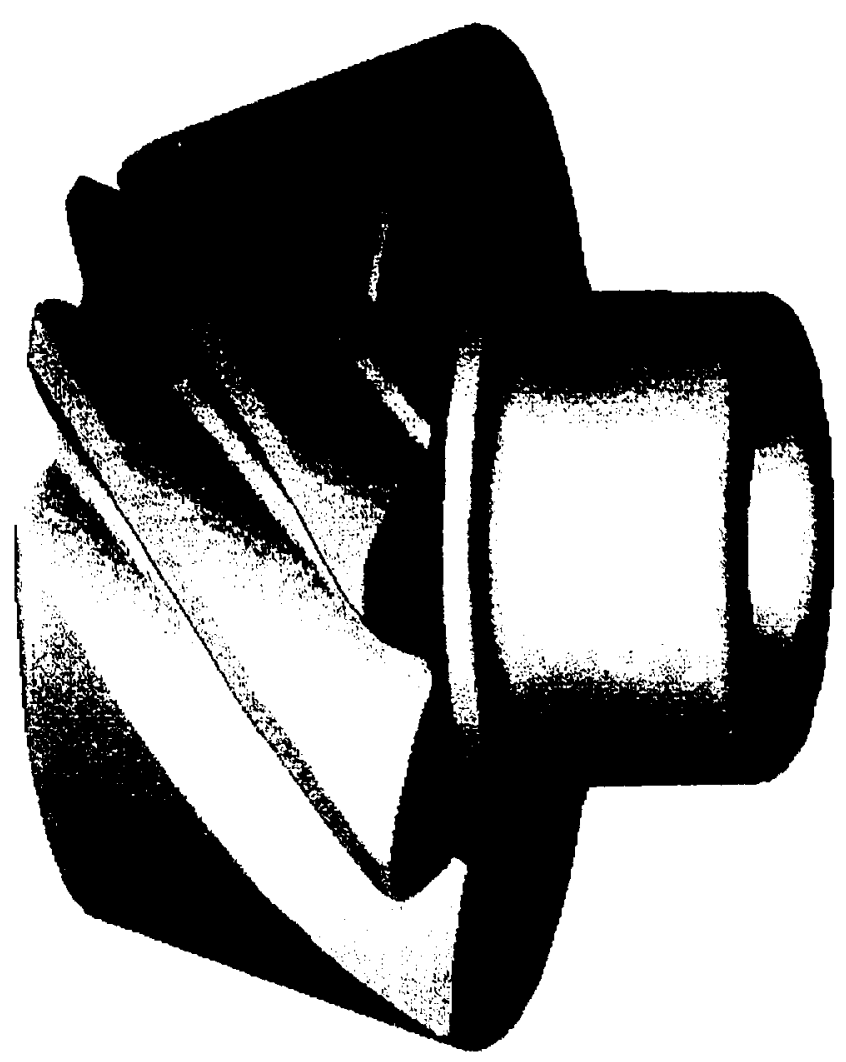

Figure 12.-Hypoid gear simulation. 
Public reporting burden for this collection of information is estimated to average 1 hour per response, including the time for reviewing instructions, searching existing data sources gathering and maintaining the data needed, and completing and reviewing the collection of information. Send comments regarding this burden estimate or any other aspect of this collection of information, including suggestions for reducing this burden, to Washington Headquarters Services, Directorate for information Operations and Reports, 1215 Jefferson Davis Highway. Suite 1204. Artington, VA 22202-4302, and to the Office of Management and Budget, Paperwork Reduction Project (0704-0188). Washington, DC 20503.

\begin{tabular}{|l|c|c|}
\hline 1. AGENCY USE ONLY (Leave blank) & $\begin{array}{c}\text { 2. REPORT DATE } \\
\text { April } 1992\end{array}$ & $\begin{array}{r}\text { 3. REPORT TYPE AND DATES COVERED } \\
\text { Tcchnical Memorandum }\end{array}$ \\
\hline
\end{tabular}

\section{TITLE AND SUBTITLE}

5. FUNDING NUMBERS

A Basis for Solid Modeling of Gear Teeth With Application in Design and Manufacture

6. AUTHOR(S)

Ronald L. Huston, Dimitrios Mavriplis, Fred B. Oswald, and

Yung Sheng Liu

\section{PERFORMING ORgANIZATION NAME(S) AND ADDRESS(ES)}

NASA Lewis Research Center

Cleveland, Ohio 44135-3191

and

Propulsion Directorate

WU-505-62-36

U.S. Army Aviation Systems Command

Cleveland, Ohio 44135-3191

9. SPONSORING/MONITORING AGENCY NAMES(S) AND ADDRESS(ES)

National Acronautics and Spacc Administration

Washington, D.C. $20546-(0) 01$

and

U.S. Army Aviation Systems Command

1L162211A47A

St. Louis, Mo. 63120-1798

\section{SUPPLEMENTARY NOTES}

Ronald L. Huston, University of Cincinnati (work funded under NASA grant NSG3-188), Cincinnati, Ohio 45221; Dimitrios Mavriplis, Miles Laboratories, Elkhart, Indiana 46515; Fred B. Oswald, NASA Lewis Research Center; Yung Sheng Liu, University of Cincinnati, Cincinnati, Ohio 45221; presently with Feng-Chia University, Taichung, Taiwan. Responsible person, Fred B. Oswald, (216) 433-3957.

12a. DISTRIBUTION/AVAILABILITY STATEMENT

Unclassified - Unlimited

Subject Category 37

\section{ABSTRACT (Maximum 200 words)}

This paper discusses a new approach to modeling gear tooth surfaces. A computer graphics solid modeling procedure is used to simulate the tooth fabrication processes. This procedure is based on the principles of differential geometry that pertain to envelopes of curves and surfaces. The procedure is illustrated with the modeling of spur, helical, bevel, spiral bevel, and hypoid gear teeth. Applications in design and manufacturing are discussed. Extensions to nonstandard tooth forms, to cams, and to rolling element bearings are proposed.

\begin{tabular}{|c|c|c|}
\hline $\begin{array}{l}\text { 14. SUBJECT TERMS } \\
\text { Gears; Computer modeli } \\
\text { bevel gears; Hypoid gear }\end{array}$ & Gear tooth geometry; Spur & s; Helical gears; $S p$ \\
\hline $\begin{array}{l}\text { 17. SECURITY CLASSIFICATION } \\
\text { OF REPORT } \\
\text { Unclassified }\end{array}$ & $\begin{array}{l}\text { 18. SECURITY CLASSIFICATION } \\
\text { OF THIS PAGE } \\
\text { Unclassified }\end{array}$ & $\begin{array}{l}\text { 19. SECURITY CLASSIFICATION } \\
\text { OF ABSTRACT } \\
\text { Unclassified }\end{array}$ \\
\hline
\end{tabular}



National Aeronautics and

Space Administration

Lewis Research Center

Cleveland, Ohio 44135

Otficial Buainese

Penalty for Private Use $\$ 300$

ADDRESS CORRECTION REQUESTED

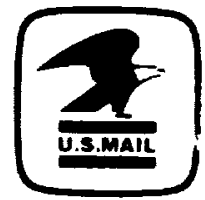

Pustaqeand Fees Patid

Nitionit Aorematuics and

Sprtet Admumstianlum

NASA 45 